\title{
The influence of factors on project management: a qualitative approach
}

\author{
José Francisco Tebaldi de Castro ${ }^{\mathrm{a} *}$ (D), Helder Gomes Costa ${ }^{\mathrm{a}}$ (D), Mirian Picinini Méxas ${ }^{\mathrm{a}}$ (D), \\ Claudio Benevenuto de Campos Lima ${ }^{a}$ (D), Wagner Rodrigues Ribeiro ${ }^{a}$ \\ a Universidade Federal Fluminense, Niterói, RJ, Brasil \\ *jftebaldic@terra.com.br
}

\begin{abstract}
Paper aims: This study describes a qualitative analysis methodology, proposing measurement of the degree of influence of factors acting in project management.

Originality: A multidisciplinary approach explores a path not previously addressed by methodologies commonly associated with project management.

Research method: The De Borda method was used on the results collected from a survey composed of two samples, and showed a strong correlation between them.

Main findings: The results suggest the need to adapt certain project management practices in a given environment, in order to preventively guarantee the success of a project during its execution. The Interpersonal Skills, with Tools and Methods, and Top Management Support are the most influential in project deployment of specific samples.

Implications for theory and practice: It covers part of the existing gap regarding the lack of knowledge on the intensity of the effects of active factors in project deployment. Researchers will be able to enhance said factors, understanding which factors determine, preventively, project success.
\end{abstract}

Keywords

Influencing factors. Critical success factor. Multi-criteria method. Project success.

How to cite this article: Castro, J. F. T., Costa, H. G., Méxas, M. P., Lima, C. B. C., \& Ribeiro, W. R. (2021). The influence of factors on project management: a qualitative approach. Production, 31, e20200112. https://doi.org/10.1590/01036513.20200112 .

Received: Nov. 13, 2020; Accepted: Apr. 07, 2021.

\section{Introduction}

The influence of not only internal factors, but also those external to an organization, occurs in project deployment, as well as in other processes. A lack of knowledge regarding the intensity of the effects caused by factors, before effective project closeout, can be considered a problem, despite the studies addressing this issue. There are studies in the literature showing the presence of factors in the development of specific projects, as well as in portfolios (Voss, 2012; Beringer et al., 2013; Meskendahl, 2010; Kock et al., 2016; Patanakul, 2015). Not knowing the effects that certain factors can have during deployment of a project is undoubtedly a genuine problem. Factors, if not managed, can lead projects to failure, as already described by authors, such as Alagba (2014), Alias et al. (2014), Belout \& Gauvreau (2004), Berssaneti \& Carvalho (2015), Cooke-Davies (2002), Dvir \& Lechler (2004), Hung et al. (2014), lhuah et al. (2014), Kuo \& Kuo (2010), Müller (2016), Nguyen et al. (2019), Qi et al. (2014), and Young \& Poon (2013). The evidence often occurs after project deployment, regarding differences between planning and execution.

After consulting different databases, hundreds of factors causing both positive and negative effects, or problems, on project management were identified. Despite the plurality found in the literature on the theme, 
one may question what could be added to the existing knowledge. Unexpectedly, no studies were found measuring the effects caused by factors on project management. Moreover, no references were found regarding the qualifications, characteristics or effects attributed to such factors.

On the other hand, there are various citations regarding the influence of factors on processes. For example, factors in the effectiveness of managing multiple projects can be cited (Patanakul \& Milosevic, 2009), the influence of strategies on portfolio management and the associated success (Meskendahl, 2010; Qi et al., 2014), the influence of factors on inter-organizational supply chain relationships (Papadonikolaki et al., 2017), the influence of key factors on process management (lamratanakul et al., 2014; Xiao et al., 2010), and the influence of stakeholders in construction projects (Nguyen et al., 2019).

Influence can be defined as the act or effect of influencing, the power exerted over people or things, interference, preponderance, or the ability to cause a result on something or someone. Therefore, the objective is to measure the degree of influence of the factors perceived by all stakeholders acting on a project through a method of qualitative analysis applied to the perceptions of selected samples.

However, for such an analysis, it is necessary to select a simple and easily applicable tool. Among the available tools are the multi-criteria decision aid (MCDA) methods. Such methods are not deterministic, they are flexible, customizable and gather information that helps in the decision-making process. They are also objective, produce immediate results and are based on robust methodological procedures (Papadonikolaki et al., 2017; Liang et al., 2016; Pan \& Nguyen, 2015; Nilashi et al., 2015). The De Borda method was thus selected to support the analysis of the proposed problem.

This study is structured as follows: Conceptual basis with the related authors, methodology, with the description of the De Borda Method and Pearson's Correlation Coefficient; results of the application of the steps defined in the previous section; discussion followed by conclusions; and, finally, references.

\section{Conceptual basis}

This item provides a summarized and non-exhaustive description of certain concepts necessary for development of the proposed study.

\subsection{Project management}

An adequate definition can be seen in Görög (2016), in which projects are the means by which organizations implement the necessary changes to achieve their goals. According to Görög (2016), the strategic role of projects is reinforced by several researchers and, due to the current turbulent environment, organizations need to manage project deployment at the organizational level.

In addition, Berssaneti \& Carvalho (2015) reinforce that project management is a result-oriented style and can be applied to any type of enterprise in any sector of the economy. Projects are not only solutions to technical problems, but also a way to improve business and to implement changes. Langston \& Ghanbaripour (2016) describe that project management is seen as a set of tools, standards and procedures, and one of the main challenges for academic research lies in its interdisciplinary nature, focused on practical problems, whose solutions require the combination of various disciplines.

There are other definitions that add value to project management, including the management of risks, deliveries, and schedules, in short, all the stages of effective project deployment. Briefly, for the purposes of the present study, project management is defined as a result-oriented process, in which initiatives are the means that organizations use to implement the necessary changes to achieve strategies aligned with the portfolio. In this process, an organization transforms inputs into valuable assets, which will produce wealth. Project management includes methodologies, artifacts, deadlines, scopes and the transdisciplinary integration of specialists in the development of solutions. (Müller, 2016; Görög, 2016; Langston \& Ghanbaripour. 2016).

\subsection{Factors}

As previously described, there are studies that present different causes that influence project success. The work of Cooke-Davies (2002) can be cited as an example, demonstrating that this subject has been researched for decades. Despite the knowledge acquired, the countless organizations that have structured themselves for project management, and also the large number of existing projects, some results have shown the need for further studies deepening the knowledge in regard to factors (Müller, 2016; Alias et al., 2014). 
Castro et al. (2019) present a comprehensive compilation of factors found in the literature, obtained from papers analyzed since 1994. Castro et al. (2019) define influencing factors as those that cause changes in processes, which can lead project deployment to failure or the detachment of corporate strategies. They are also known as critical success factors (CSF), attributes or necessary requirements contributing positively or negatively to the activities of organizational processes. For this study, this will be the definition adopted.

As described in Castro et al. (2019), the following steps were adopted for document selection and factor identification: a) Definition of the research theme; b) Definition of the guiding questions; c) Choice of keywords; d) Database selection; e) Criteria selection; f) Reading of the titles and abstracts; and g) Registration of the documents on Mendeley software.

A manual check was made using the Mendeley application to consolidate the results. Subsequently, through consulting the references of the selected articles, new documents were obtained in relation to the processes and methods addressed. A search on the defined databases, using driven queries, was performed. As a result, a set of 258 documents was identified. After screening, using the selection criteria, the core of the research was restricted to 68 documents.

The selected articles were analyzed in depth for influencing factors. In this step, 496 factors were initially found, which were then reduced through deeper analysis structured in steps, as per Figure 1.

The selection criteria resulted in a group of 27 influencing factors. However, 12 of these were chosen based on the number of citations (ten or more), as well as the number of years between the first and the last citation found for each factor. It is interesting to note that none of the discarded factors appear after the year 2016. So, all of them had time to be cited and no recent factor in the literature has been ruled out. Thus, it was possible to choose those with the highest incidence in recent years, mainly in project management and portfolio management.

\subsection{Multicriteria methods}

There has been much research on the development of scientific formulations of the decision-making process within a subjective context over the past few centuries. Llull's work on papal election, Condorcet's work on the decisions of jurors in court, De Borda's work on political elections in France, Pareto's work with conflicting criteria, and the development of the Multi-Attribute Utility Theory (MAUT), are some examples described in Costa (2017).

According to Costa (2017), from the 1960s onwards, Multi-criteria Decision Aid (MCDA) gained its own identity and terminology, with emphasis on the works of Bernard Roy and Thomas L. Saaty. Roy's works gave rise to ELECTRE methods, and Saaty's work gave rise to AHP and its variations. The PROMETHEE method and MACBETH were also developed. Internal variations in said methods resulted in new multi-criteria methods. In addition, there are methodologies that interact with MCDA such as Fuzzy Sets, Fuzzy Logic and Neural Networks.

Multi-criteria methods are used to assist decision-makers in choosing from alternatives. Dinmohammadi \& Shafiee (2017) state that multi-criteria approaches assist decision makers in the treatment of diverse information,

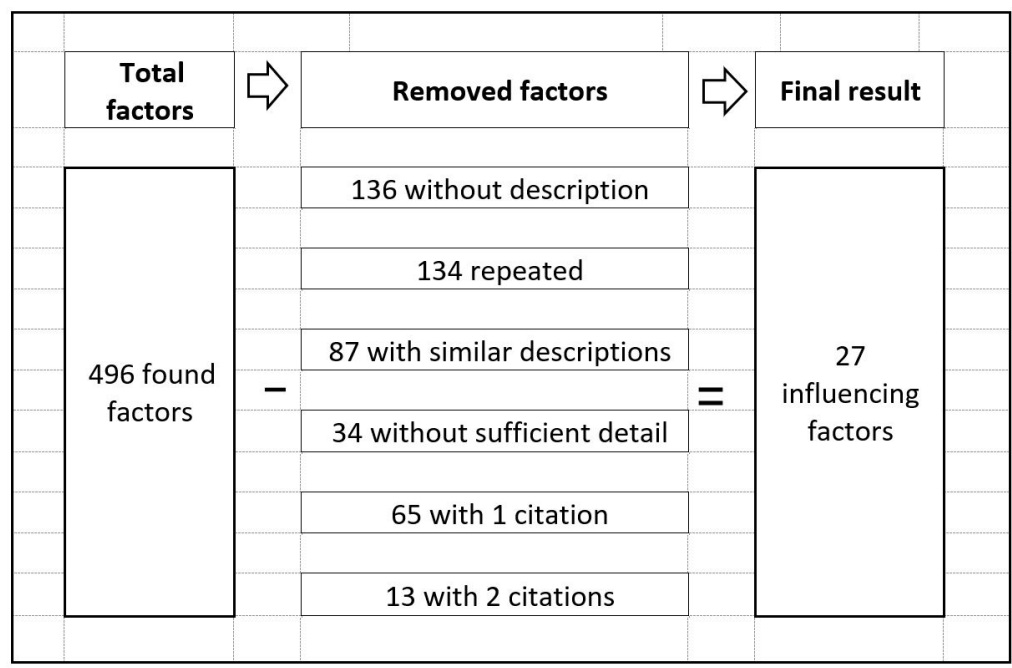

Figure 1. Refinement of factors (from Castro et al., 2019). 
involving preferences, and interconnected or contradictory criteria in uncertain environments. Such approaches should be used in a neutral, objective and transparent environment, without the intention of indicating a single solution. Given the context of this study, the multi-criteria approach is the most appropriate and the De Borda method was chosen for its simplicity and ease of application.

\subsubsection{De Borda method}

This method was presented in France in 1781 by Jean-Charles De Borda, being recognized in 1794 by the French Academy of Sciences and adopted in elections with numerous electors. The aim of the method is to build a ranking of alternatives, from the best to the worst (Costa, 2017). According to Silva (2015), the De Borda method is an ordinal multi-criteria evaluation method, being, in essence, the evaluation of the alternatives that best fit the defined criteria. To use this method, the elector must order the alternatives according to their preferences; the preferred alternative receives the highest score, the second alternative receives the second highest score, and so on. At the end, the points attributed by every elector to each alternative are added up, and the alternative with the highest score is chosen. During application of the method, all choices are made voluntarily, democratically and without any induction. As described in McLean (1990) and Barba-Romero \& Pomerol (1997), the central idea of this method is to establish a combination of the rankings of the decision makers on a global ranking.

Studies using the De Borda method in the aerospace sector, in risk assessment and operational safety at airports (Gonçalves \& Correia, 2015), in service quality assessment provided at civil aviation airport terminals (Rocha et al., 2016), and in the analysis of disruptive innovations in startups (Gavião et al., 2016) are examples that validate its applicability.

\section{Methodology}

The De Borda method was applied to the data obtained on a survey collecting the perceptions of specialists from two different samples. In the second step, an analysis of the sensitivity of the results to the modeling parameters was performed using Pearson's Correlation Coefficient. More specifically, based on the works of Costa (2017), the following steps of the De Borda method were performed as described below.

A. Define the evaluators;

B. Define the elements that will be ranked by the evaluators;

C. Obtain each evaluator's perception of each element. The evaluators can vote for more than one element, albeit limited to the maximum number (n) of allowed elements. Each evaluator votes as follows:

i. Assign the grade $n$ to the alternative that the evaluator considers the best option;

ii. Assign the grade $n-1$ to the alternative considered the second-best option;

iii. Repeat the task until the evaluator completes $n$ votes. These steps must be repeated with all evaluators.

To perform the assessment following the steps described above, the form was structured according to the Likert-type scale, shown in Table 1.

D. The next step is to sum the received grades for each element. The element with the highest score is considered the first option, the second highest score as the second option, and so on;

E. Obtain the final ranking of the evaluated elements, which will reflect the preference order of the elements in the evaluators' perception, with the first position being the most accepted by all.

Table 1. Likert-type scale.

\begin{tabular}{cc}
\hline Numerical & Verbal Scale of Preferences \\
\hline-2 & High negative influence \\
-1 & Average negative influence \\
0 & No influence \\
1 & Average Positive Influence \\
2 & High positive influence \\
\hline
\end{tabular}


Descriptive statistical analysis should be used to help with a more direct and simpler visual language, when two samples are considered. In addition, subjective, regional or organizational effects are eliminated. The analysis must be developed based on the Pearson Correlation Coefficient.

F. Measure the Pearson Correlation Coefficient (the degree of correlation, as well as the positive or negative direction) between two metric scale variables.

Variables are associated statistically when they have similarities in the distribution of their scores. In Pearson's correlation, the association occurs by measuring the variance shared between the two considered variables. The coefficient is used when the two variables under study are normally distributed. A value of 1 or -1 for the coefficient means that the correlation is perfect (positive or negative). If it is equal to zero, it means that the two variables do not depend linearly on each other, however, there may be a non-linear dependence. In this case, the result should be investigated by other methods.

The coefficient should be obtained using two steps: The first one is to set up a table with the final rankings of the two samples for the selected factors, obtained in the previous step. Measurement by ranking disregards the different sample sizes. The second step is to calculate the Pearson Correlation Coefficient between the two rankings for the factors, according to the following equation:

$$
r=\frac{1}{n-1} \cdot \sum\left(\frac{x i-\bar{X}}{S x}\right) \cdot\left(\frac{y i-\bar{Y}}{S y}\right)
$$

Where:

$r$ - Pearson's Correlation Coefficient;

$n$ - number of considered factors;

$x$ and $y$-variables with the factor's position in the rankings in the two samples;

$S x$ and $S y$ - standard deviation for each variable;

$\bar{X}$ and $\bar{Y}$ - arithmetic mean of each sample position.

\section{G. Define axes and areas of influence}

The scales of the abscissa and ordinate axes must follow the model shown in Figure 2. For construction of the graph, with the positions of the factors' influence, two samples are necessary, where " $\mathrm{n}$ " is the largest sum of the scores attributed to the factors in sample 1 . This sum will signal the scale limit on the abscissa axis. Likewise, " $m$ " is the largest sum of sample 2 and will signal the scale limit on the ordinate axis.

Each axis should be divided into three parts, defining areas of low, medium and high influence, as shown in Figure 2.

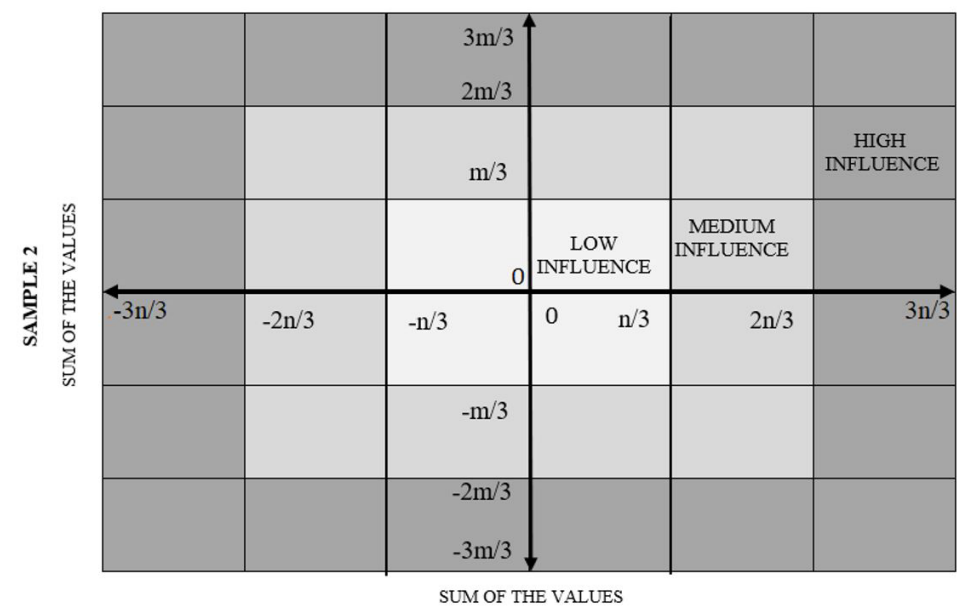

SAMPLE 1

Figure 2. Influence scale of factors. 


\section{$\mathrm{H}$. Measure the degree of influence}

The measurement should be obtained using four steps. The first is to obtain the position $(x, y)$ in the table of final rankings, according to step $F$, using sample 1 on the abscissa axis and sample 2 on the ordinate axis. The position of each factor defines its influence. The second is to calculate the arithmetic means between the positions in the two samples for each factor. The third is to calculate the final ranking, assigning a value of 1 to the most influential factor with the lowest arithmetic mean, 2 for the second lowest arithmetic mean and so on until the last value. The last step is, based on the ordering of the previous step, determining the diameter of each factor, using a bubble graph, whereby the bubble diameter will be the inverse of the final order, that is, the first factor of the order (number 1 being the greatest influence) receives a diameter equal to the number of factors considered. The second receives a diameter equal to the previous one subtracted from 1, and so on until the last factor. The bubble diameter defines the degree of influence of the factor on the process.

\section{Modeling results}

This section presents the results of the application of the steps defined in the previous section, which resulted in the ranking of the influence of factors on project management.

\section{A. Define the evaluators}

In order to minimize the environmental, regional, organizational and subjective aspects and to evaluate response behavior, the survey covered two samples. The first sample, named Market, was generic and represented the external project environment. The second, named Z, on the other hand, was specific and represented the company environment where the project is inserted.

B. Define the elements that will be ranked by the evaluators

The twelve most cited factors in the bibliographic survey are presented in Table 2 and are the elements taken for evaluation by the samples.

Table 2 shows that 9 factors had their first citations in the literature prior to 2004, while the others are prior to 2010. On the other hand, 11 factors were cited in documents from 2016, indicating that their influence is current in organizational processes. Thus, it is evident that the choice of factors for analysis is consistent with those most cited in the literature.

As already described, the factors applied in the proposed method were obtained through a previous bibliographic study and should be considered as examples only. However, other factors may be identified according to the requirements of a specific project.

\section{Obtain each evaluator's perception of each element}

The value judgments issued by the evaluators were collected with the support of an online form available on the Survey Monkey application (http // www.surveymonkey.com). The form link was sent to specialists who made up the two samples. At the end of the survey, a total of 56 valid questionnaires were obtained for the Market sample and 120 for the $\mathrm{Z}$ sample.

Table 3 shows, as an example, the Market sample evaluators' responses in a question on the form, according to the scale presented in Table 1. Each factor was graded from (-2) to (+2), considering the influence on project management.

Table 2. Most cited factors.

\begin{tabular}{ccccc}
\hline \multirow{2}{*}{ Factor } & Name & Number of Citations & \multicolumn{2}{c}{ Year of citation } \\
\cline { 3 - 4 } & & & First citation & Last citation \\
\hline F1 & Top Management Support & 16 & 2004 & 2016 \\
F2 & Risks & 14 & 2000 & 2016 \\
F3 & Business Alignment & 12 & 2000 & 2016 \\
F4 & Roles and Responsibilities & 14 & 2003 & 2016 \\
F5 & Stakeholder Pressures & 12 & 2004 & 2016 \\
F6 & Changes & 14 & 2003 & 2016 \\
F7 & Tools and Methods & 12 & 2003 & 2016 \\
F8 & Interdependencies & 12 & 2000 & 2016 \\
F9 & Information Technology & 10 & 2010 & 2016 \\
F10 & Interpersonal Skills & 11 & 2010 & 2016 \\
F11 & Organisational culture & 10 & 2009 & 2016 \\
F12 & Resource Sharing & 11 & 2000 & \\
\hline
\end{tabular}

Adapted from Castro et al. (2019). 
Table 3. Market sample evaluation.

\begin{tabular}{|c|c|c|c|c|c|c|c|c|}
\hline \multicolumn{2}{|c|}{ Influencing Factors } & $\begin{array}{l}\text { High negative } \\
\text { influence }\end{array}$ & $\begin{array}{c}\text { Average negative } \\
\text { influence }\end{array}$ & $\begin{array}{c}\text { No } \\
\text { influence }\end{array}$ & $\begin{array}{l}\text { Average positive } \\
\text { influence }\end{array}$ & $\begin{array}{l}\text { High positive } \\
\text { influence }\end{array}$ & $\begin{array}{c}\text { No } \\
\text { opinion }\end{array}$ & Total \\
\hline & Likert-type scale & $(-2)$ & $(-1)$ & 0 & $(+1)$ & $(+2)$ & $(--)$ & \\
\hline $\mathrm{F} 1$ & $\begin{array}{c}\text { Top Management } \\
\text { Support }\end{array}$ & 1 & 3 & 2 & 20 & 30 & 0 & 56 \\
\hline F2 & Risks & 7 & 13 & 1 & 9 & 25 & 1 & 56 \\
\hline F3 & $\begin{array}{c}\text { Business } \\
\text { Alignment }\end{array}$ & 1 & 2 & 4 & 25 & 21 & 2 & 55 \\
\hline $\mathrm{F} 4$ & $\begin{array}{c}\text { Rules and } \\
\text { Responsibilities }\end{array}$ & 0 & 3 & 6 & 17 & 28 & 1 & 55 \\
\hline F5 & $\begin{array}{l}\text { Stakeholder } \\
\text { Pressures }\end{array}$ & 9 & 13 & 3 & 9 & 16 & 5 & 55 \\
\hline F6 & Changes & 12 & 13 & 2 & 10 & 17 & 1 & 55 \\
\hline F7 & Tools and Methods & 1 & 3 & 3 & 21 & 26 & 1 & 55 \\
\hline F8 & Interdependencies & 6 & 7 & 6 & 16 & 17 & 2 & 54 \\
\hline F9 & $\begin{array}{l}\text { Information } \\
\text { Technology }\end{array}$ & 1 & 1 & 5 & 26 & 20 & 1 & 54 \\
\hline F10 & Interpersonal Skills & 1 & 0 & 3 & 17 & 32 & 2 & 55 \\
\hline $\mathrm{F} 11$ & $\begin{array}{c}\text { Organizational } \\
\text { Culture }\end{array}$ & 5 & 5 & 2 & 21 & 20 & 2 & 55 \\
\hline F12 & Resource Sharing & 2 & 6 & 4 & 26 & 15 & 1 & 54 \\
\hline
\end{tabular}

Table 4. Final rankings.

\begin{tabular}{|c|c|c|c|c|}
\hline \multicolumn{5}{|c|}{ FINAL RANKING } \\
\hline \multicolumn{5}{|c|}{ EVALUATORS' PERCEPTION } \\
\hline \multirow{2}{*}{ FACTOR } & \multicolumn{2}{|c|}{ MARKET SAMPLE } & \multicolumn{2}{|c|}{ Z SAMPLE } \\
\hline & Sum of assigned values & Factor Ranking & Sum of assigned values & Factor Ranking \\
\hline $\mathrm{F} 1$ & 71 & 1 & 137 & 5 \\
\hline $\mathrm{F} 2$ & 18 & 10 & 5 & 9 \\
\hline F3 & 57 & 4 & 138 & 4 \\
\hline $\mathrm{F} 4$ & 56 & 5 & 139 & 3 \\
\hline F5 & 5 & 12 & -116 & 12 \\
\hline F6 & 8 & 11 & -78 & 11 \\
\hline F7 & 60 & 3 & 143 & 2 \\
\hline F8 & 24 & 9 & -4 & 10 \\
\hline F9 & 54 & 6 & 119 & 6 \\
\hline F10 & 67 & 2 & 144 & 1 \\
\hline $\mathrm{F} 11$ & 39 & 7 & 67 & 7 \\
\hline $\mathrm{F} 12$ & 28 & 8 & 36 & 8 \\
\hline
\end{tabular}

\section{Sum the received grades for each element}

Table 4 shows the sum of the grades attributed to the 12 factors in the two samples, in the second and fourth columns. Each evaluator scored the 12 factors within the scale shown in Table 1.

E. Obtain the final ranking of the evaluated elements

Table 4 presents the final ranking of the grades attributed to the 12 factors in the two samples, in the third and fifth columns. With the values ranked using the De Borda method, it was possible to compare the two samples using Graph 1.

\section{F. Measure the Pearson Correlation Coefficient}

The first step is to prepare a table with the final rankings of the two samples. As already described, the scores obtained in the two samples using the De Borda method were presented in Table 4. The second one is to calculate Pearson's Correlation Coefficient. Apply Equation 1 with the third and fifth columns of Table 4 to obtain Pearson's Correlation Coefficient $(r)$. 


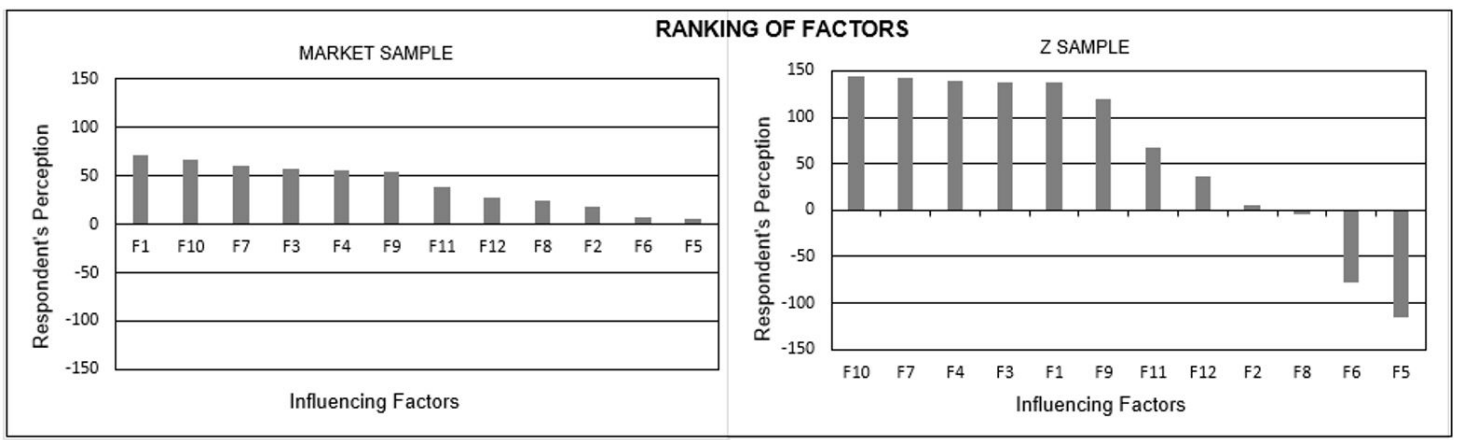

Graph 1. Factors Ranking.

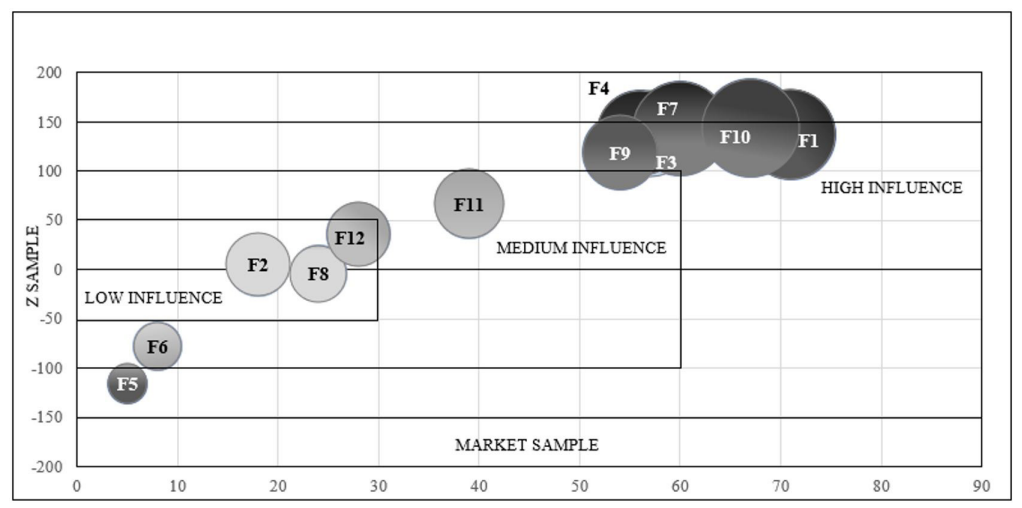

Graph 2. Final Influence for Project Management.

The result indicated a strong correlation between the perceptions of the samples. As the proposed method is not specific to an organization, there was a strong possibility that the results would not be correlated, since the samples are independent and have different profiles. However, this was not the case.

\section{G. Define axes and areas of influence}

The scales were obtained according to Figure 2, based on the highest and lowest scores obtained in the samples. For the Market sample, the scores were between zero and 71 . The chosen limits were zero and 90 , to facilitate graphical representation. In Z sample, the extremes were -116 and 144 . The chosen limits were -150 and 200 . The axes were divided into three parts to define the areas.

\section{$\mathrm{H}$. Measure the degree of influence}

The first step is to obtain the position $(x, y)$ in the table with the final rankings. The third column in Table 4 is associated with the abscissa $(x)$ axis and the fifth column with the ordinate $(y)$ axis. For each factor, a pair $(x, y)$ was formed, which should be plotted graphically. Then, the second step is calculating arithmetic means between the positions of samples for each factor. Table 5 presents, in the sixth column, the arithmetic means, considering the third and the fifth columns.

The third step is to calculate the final ranking. For this, ranking 1 was assigned to the factor of greatest influence with the lowest arithmetic mean, 2 to the second lowest mean and so on until the last mean. Table 5 shows the final ranking in the last column. For example, the F10 factor (Interpersonal Skills) had the lowest arithmetic mean and was number 1 in the ranking.

The last step is determining the degree of influence of each factor. The influence of a factor is the inverse of the final order obtained in Table 5, that is, factor number 1 of the order receives a diameter equal to 12, which is the number of factors considered. The last column of Table 6 summarizes all the steps to determine the degree of influence of selected factors on project management, according to the respondents.

With the determination of the degree of influence of each factor, it is possible to complete the bubble graph. Graph 2 shows the distribution of the influence of the factors considered in this study on project management, according to the samples. 
Table 5. Final ranking.

\begin{tabular}{|c|c|c|c|c|c|c|}
\hline \multicolumn{7}{|c|}{ FINAL RANKING } \\
\hline \multirow{2}{*}{ FACTORS } & \multicolumn{2}{|c|}{ MARKET SAMPLE } & \multicolumn{2}{|c|}{ Z SAMPLE } & \multirow{2}{*}{$\begin{array}{l}\text { Arithmetic mean } \\
\text { of ranking }\end{array}$} & \multirow{2}{*}{ Final Ranking } \\
\hline & Total (Table 4) & Ranking (Table 4) & Total (Table 4) & Ranking (Table 4) & & \\
\hline F1 & 71 & 1 & 137 & 5 & 3.0 & 3 \\
\hline $\mathrm{F} 2$ & 18 & 10 & 5 & 9 & 9.5 & 8 \\
\hline F3 & 57 & 4 & 138 & 4 & 4.0 & 4 \\
\hline $\mathrm{F} 4$ & 56 & 5 & 139 & 3 & 4.0 & 4 \\
\hline F5 & 5 & 12 & -116 & 12 & 12.0 & 11 \\
\hline F6 & 8 & 11 & -78 & 11 & 11.0 & 10 \\
\hline F7 & 60 & 3 & 143 & 2 & 2.5 & 2 \\
\hline F8 & 24 & 9 & -4 & 10 & 9.5 & 9 \\
\hline F9 & 54 & 6 & 119 & 6 & 6.0 & 6 \\
\hline F10 & 67 & 2 & 144 & 1 & 1.5 & 1 \\
\hline F11 & 39 & 7 & 67 & 7 & 7.0 & 7 \\
\hline $\mathrm{F} 12$ & 28 & 8 & 36 & 8 & 8.0 & 8 \\
\hline
\end{tabular}

Table 6. Influence of factors on project management.

\begin{tabular}{|c|c|c|c|c|c|c|c|c|}
\hline \multicolumn{9}{|c|}{ INFLUENCE OF FACTORS ON PROJECT MANAGEMENT } \\
\hline \multirow[b]{3}{*}{ FACTORS } & \multicolumn{7}{|c|}{ RESPONDENTS' PERCEPTION } & \multirow{3}{*}{$\begin{array}{l}\text { Influence } \\
\text { Degree } \\
\text { (Bubble Size) }\end{array}$} \\
\hline & \multicolumn{2}{|c|}{ MARKET SAMPLE } & \multicolumn{2}{|c|}{ Z SAMPLE } & \multirow{2}{*}{$\begin{array}{l}\text { PEARSON } \\
\text { Correlation } \\
\text { Coefficient }\end{array}$} & \multirow{2}{*}{$\begin{array}{c}\text { Arithmetic } \\
\text { mean of } \\
\text { ranking }\end{array}$} & \multirow[b]{2}{*}{ Final Ranking } & \\
\hline & $\begin{array}{c}\text { Total } \\
\text { (Table 4) }\end{array}$ & $\begin{array}{l}\text { Ranking } \\
\text { (Table 4) }\end{array}$ & $\begin{array}{c}\text { Total } \\
\text { (Table 4) }\end{array}$ & $\begin{array}{l}\text { Ranking } \\
\text { (Table 4) }\end{array}$ & & & & \\
\hline F1 & 71 & 1 & 137 & 5 & \multirow{12}{*}{0.916084} & 3.0 & 3 & 10 \\
\hline F2 & 18 & 10 & 5 & 9 & & 9.5 & 8 & 5 \\
\hline F3 & 57 & 4 & 138 & 4 & & 4.0 & 4 & 9 \\
\hline $\mathrm{F} 4$ & 56 & 5 & 139 & 3 & & 4.0 & 4 & 9 \\
\hline F5 & 5 & 12 & -116 & 12 & & 12.0 & 11 & 2 \\
\hline F6 & 8 & 11 & -78 & 11 & & 11.0 & 10 & 3 \\
\hline F7 & 60 & 3 & 143 & 2 & & 2.5 & 2 & 11 \\
\hline F8 & 24 & 9 & -4 & 10 & & 9.5 & 9 & 4 \\
\hline F9 & 54 & 6 & 119 & 6 & & 6.0 & 6 & 7 \\
\hline F10 & 67 & 2 & 144 & 1 & & 1.5 & 1 & 12 \\
\hline F11 & 39 & 7 & 67 & 7 & & 7.0 & 7 & 6 \\
\hline $\mathrm{F} 12$ & 28 & 8 & 36 & 8 & & 8.0 & 8 & 5 \\
\hline
\end{tabular}

\section{Discussion}

The evaluations presented in Graph 1 signal the evaluators' perceptions in the two samples. If only one of them were taken as the most true, one could fall into an error of assessment. Aspects that the answers do not reveal, such as the moment of the survey or the characteristics of the sample, are not only random, but also personal and cannot be considered. Such characteristics add variations that hinder a clear and definitive analysis. This can be observed, for example, in factors Interdependencies (F8), Organizational Culture (F11) and Resource Sharing (F12), in which, for the Market sample, the influence was more evident in positive evaluations, in contrast to the $\mathrm{Z}$ sample.

It is possible to see in Graph 1 which factors are the most influential per sample, albeit without considering the absolute values of the scores, since the sample totals are different. It is observed that the orders have reasonable differences when comparing one sample with another. The influences of the organizational characteristics and the environment where the organization is inserted affect the final ranking, with the appearance of subjective aspects. This fact can be observed in factors Stakeholder Pressures (F5) and Changes (F6) in the Z sample, which are very negative when compared to the Market sample.

Likewise, in Graph 1, which shows the final score with the application of the De Borda method, there are also difficulties in the best ordering to be adopted, although the results between the two samples were close. This can be demonstrated from the sixth position obtained in the final ranking - Information Technology (F9). From this factor onwards, the sequence of positions is almost identical between the two samples. However, for 
the first positions, the results are different. To choose the factor of greatest influence for the development of enhancing actions, for example, one should consider not only one factor, but all of the highest scores.

On the other hand, it can be seen in Graph 2 that factors Interpersonal Skills (F10), Tools and Methods (F7), Top Management Support (F1), Roles and Responsibilities (F4), Business Alignment (F3), and Information Technology (F9) are in the high influence region. It is important to note that factor Stakeholder Pressures (F5) is also found in the high influence region, but with a negative value. The same fact occurred with factor Changes (F6), located in the medium influence region. Müller (2016) points out that changes in policies and priorities act as external environmental factors that affect success in project management. Such factors are perceived primarily in stakeholder and change management.

By combining the Likert-type scale for evaluations, with the De Borda method and Pearson's Correlation Coefficient, the proposed method not only eliminates the characteristics of the samples, but also orders, transparently, the factors of greatest influence.

As a result of the proposed method, the Interpersonal Skills of the teams (F10), with appropriate and integrated Tools and Methods (F7), associated with Top Management Support (F1) are the most influential in project deployment of specific samples. The project manager must preventively act on said factors to ensure project success. The Business Alignment (F3) of all teams involved with the project, with defined Roles and Responsibilities (F4) and the support of Information Technology hardware and software (F9) complement the list. In summary, the factor positions in Graph 2, with the ranking obtained, highlights this fact.

Although certain factors are highlighted as the most influential, the proposed method does not define how each of them should be treated. The project manager and the project management office should ascertain how they will be controlled, as there are no specific project management practices to deal with any given influencing factor. Thus, some actions must be considered in order to enhance the main factors identified, some of which are described below in Table 7.

In the example used in the method presentation, factors such as changes and stakeholder pressures can be addressed in existing project management practices. The same cannot be said about resource sharing, for example. Thus, although the method is generic for any situation, the factors are not, and should be chosen according to the environment in which the projects are inserted, and the existence of practices that control them.

How might the results help a project manager involved in project deployment? First, it is necessary to understand what this study proposes, that is, to measure the degree of influence of factors acting in project

Table 7. Proposed actions.

\begin{tabular}{|c|c|c|}
\hline & Influencing Factors & Proposed Actions \\
\hline F10 & Interpersonal Skills & $\begin{array}{l}\text { Definition of personal characteristics and selection of professionals with such characteristics for the } \\
\text { development of tasks that add value or execution in the organization key-positions; } \\
\text { Promotion of cooperation, organizational involvement and trust through example and proactive } \\
\text { attitudes. }\end{array}$ \\
\hline F7 & Tools and Methods & $\begin{array}{l}\text { Development of systems to integrate different organizational areas, but in line with business objectives; } \\
\text { Development of new ideas that facilitate work and increase productivity with motivation and dedication; } \\
\text { Standardization of work tools, allowing functional mobility; } \\
\text {. Implementation of forums for sharing ideas, stimulating the dissemination of new working methods in } \\
\text { organizational processes. }\end{array}$ \\
\hline $\mathrm{F} 1$ & Top Management Support & $\begin{array}{l}\text { Support and recognition of project managers and functional managers authority; } \\
\text { Development of suitable organizational structures for different processes, enabling the formation and } \\
\text { fusion of hybrid structures; } \\
\text { Stimulating communication and employee participation; } \\
\text {. Development of a management model that facilitates the decision-making process. }\end{array}$ \\
\hline F3 & Business Alignment & $\begin{array}{l}\text { Promotion of organizational structures suitable to business strategies; } \\
\text { Recognition of all parts of the organization as vital to achieving results; } \\
\text {. Clear communication of the vision, mission, strategic objectives and organizational goals; } \\
\text {. Promotion of the monitoring and control of strategic objectives connected to the results. }\end{array}$ \\
\hline F4 & Roles and Responsibilities & $\begin{array}{l}\text { Clear definition of the roles and attributions of the entire management structure; } \\
\text { Simplification of the organizational structure to the minimum necessary for the management model } \\
\text { operation; } \\
\text {. Promotion of connected, distinct and independent structures. }\end{array}$ \\
\hline F9 & Information Technology & $\begin{array}{l}\text { Application of technological solutions that promote the integration, storage, access, security and } \\
\text { updating of information; } \\
\text {. Communication of technologies available to the entire organization, promoting the standardization of } \\
\text { systems and softwares; } \\
\text {. Training of teams and managers in the available technologies. }\end{array}$ \\
\hline
\end{tabular}


management. The presented method helps to answer "how" to measure this, considering representative samples. How are stakeholders involved in this question? If the stakeholders are represented in the sample, influencing factors will then be very close to corporate expectations. For example, a civil engineering projects company has a very different structure to one with industrial facilities and this will be reflected in the choice of factors. However, the proposed method can be used to identify influencing factors in any enterprise. As such, the method must be known in advance, through samples of representative stakeholders. The survey in the present study did not have the bias of a specific company, but signalled the consistency of results, even with a generic sample of specialists.

According to Dvir \& Lechler (2004), even with the link between the project portfolio and corporate strategies, reality presents a variety of unforeseen events, both within and outside organizations. Despite the extensive literature addressing factors in the processes, particularly project management, no studies have been found that associate the influence of factors with the qualifications, characteristics, or quantifiable effects attributed to them.

There are examples in the literature of the influence of factors on effectiveness in portfolios composed of multiple projects with limited resources (Patanakul \& Milosevic, 2009), in portfolio strategies and their associated success (Meskendahl, 2010; Qi et al., 2014), in inter-organizational relationships in supply chains (Papadonikolaki et al., 2017), and in process management with key success factors (Xiao et al., 2010). Despite the high incidence of articles on the influence of factors, no article has provided a clear definition of this, which highlights a gap in the literature that this study aims to fill.

The plurality of the samples reinforces the obtained result, without showing a trend, such as the influence of a type of market. This, however, cannot be verified with factors F5 (Stakeholder Pressures) and F6 (Changes), where the perception brought by the $\mathrm{Z}$ sample was very striking, due to the political and economic environment experienced in recent years in the organization in which the sample was inserted. Even so, the two samples signaled the negative influence of these two factors, which should also demand organizational attention. It can be inferred that the more multidisciplinary the sample, the better the measurement of the real perception of the most influential factors. This fact can be observed in the characteristics of the samples presented below.

Sample 1, denominated "Market", was consisted of professionals from different segments, with high levels of professional experience and education, with participants from 15 countries. Forms were sent to the participants via 20 communities on linkedln. Among the market segments surveyed, Information Technology (IT), Project Management Office (PMO), and Transport and Construction, represented 42\% of the total. In the sample, 60\% of the professionals had more than 20 years' experience, $60 \%$ had a Master's degree, $22 \%$ had a Post-Graduate qualification and $8 \%$ had a Doctorate, reflecting very high levels of education and experience.

Sample 2, denominated "Z", was composed of participants from a Brazilian Oil \& Gas company. This segment was excluded from the previous sample so as not to interfere with the results. In this sample $44 \%$ of the total had over 20 years' professional experience and 30\% over 30 years. The academic profile was composed of $40 \%$ with a Post-Graduate qualification, 29\% were Graduates and 26\% had a Master's degree. The sum of PostGraduate qualifications, Master's and Doctorates was 68\%, also representing a high level of academic education.

\section{Conclusions}

The proposed method is a multidisciplinary approach that explores a path not previously addressed by methodologies commonly associated with project management, and combines descriptive statistical analysis with multicriteria model.

The combination of the De Borda method with Pearson's Correlation Coefficient enabled:

i. A study with distinct and independent samples. This step was essential to eliminate the effect of the sectoral perception of the samples. Despite different results in the evaluations, Pearson's Correlation Coefficient showed a strong correlation, signaling a coherent final ranking;

ii. Measurement of the degree of influence of each factor, according to the environment in which the project is deployed, based on the perception of different, independent samples formed by participants with proven professional and academic experience. This point is highly relevant, as it covers part of the gap identified in the bibliographic research, regarding the lack of knowledge on the intensity of the effects of active factors in project deployment;

iii. Application of the De Borda method with Pearson's Correlation Coefficient as a simple, practical and neutral method to measure the degree of influence of factors present in project management, with conclusive results; 
iv. Knowledge of the need to adapt project management practices in a given environment, considering the influencing factors, in order to preventively guarantee the success of a project during its execution;

v. Understanding of which influencing factors determine project success;

vi. The application of the De Borda method on chosen factors enabled the ordering and measurement of the influence of each factor, with emphasis on Interpersonal Skills, Tools and Methods, Top Management Support, Business Alignment, Roles and Responsibilities, and Information Technology, in the experts' perception in the two samples.

As a contribution to future research, new studies may be developed, testing other multi-criteria methods for analyzing influence. Such methods can verify if there are changes in the ranking of factors, and if the factors chosen by one method change with another method used.

Another point that must be addressed is the assessment of different factors from those addressed in this study. As previously described, the factors used were the result of extensive bibliographic research. However, it is not rigid and should not be considered as definitive. For each project, the boundary conditions must be defined and a new set of factors may be verified.

The results obtained in this study may vary in intensity and in obtained order, due to the time dynamics and the chosen population. Nevertheless, replication of the method remains valid for other publics and situations. As this study is based on results obtained in samples, the aspects of temporariness and composition of the evaluators should not be overlooked, as was reported in sample Z. To minimize this, the use of two samples is recommended.

\section{References}

Alagba, T. J. (2014). Improving drilling performance through deployment of 12-project management critical success factors: an empirical investigation. In Proceedings of the SPE Eastern Regional Meeting (SPE-171033-MS, 392-417). Texas: Society of Petroleum Engineers. http://dx.doi.org/10.2118/171033-MS.

Alias, Z., Zawawi, E. M. A., Yusof, K., \& Aris, N. M. (2014). Determining critical success factors of project management practice: a conceptual framework. Procedia: Social and Behavioral Sciences, 153, 61-69. http://dx.doi.org/10.1016/j.sbspro.2014.10.041.

Barba-Romero, S., \& Pomerol, J. C. (1997). Decisiones multicritério: Fundamentos teóricos y utilizacion prática (Colección Economía). Madrid: Universidad de Alcalá.

Belout, A., \& Gauvreau, C. (2004). Factors influencing project success: the impact of human resource management. International Journal of Project Management, 22(1), 1-11. http://dx.doi.org/10.1016/S0263-7863(03)00003-6.

Beringer, C., Jonas, D., \& Kock, A. (2013). Behavior of internal stakeholders in project portfolio management and its impact on success. International Journal of Project Management, 31(6), 830-846. http://dx.doi.org/10.1016/j.jproman.2012.11.006.

Berssaneti, F. T., \& Carvalho, M. M. (2015). Identification of variables that impact project success in Brazilian companies. International Journal of Project Management, 33(3), 638-649. http://dx.doi.org/10.1016/j.ijproman.2014.07.002.

Castro, J. F. T. D., Costa, H. G., Méxas, M. P., Lima, C. B. C., \& Caiado, R. G. G. (2019). Influencing factors in a portfolio of projects and operations: a systematic review. International Journal of Project Organisation and Management, 11(4), 311-342. http://dx.doi. org/10.1504/IJPOM.2019.104198.

Cooke-Davies, T. J. (2002). The "real' success factors on project. International Journal of Project Management, 20(3), 185-190. http:// dx.doi.org/10.1016/S0263-7863(01)00067-9.

Costa, H. G. (2017). AHP-De Borda: a hybrid multicriteria ranking method. Brazilian Journal of Operations \& Production Management, 14(3), 281-287. http://dx.doi.org/10.14488/BJOPM.2017.v14.n3.a1.

Dinmohammadi, A., \& Shafiee, M. (2017). Determination of the most suitable technology transfer strategy for wind turbines using an integrated AHP-TOPSIS decision model. Energies, 10(5), 1-17. http://dx.doi.org/10.3390/en 10050642.

Dvir, D., \& Lechler, T. (2004). Plans are nothing, changing plans is everything: the impact of changes on project success. Research Policy, 16(1), 1-15. http://dx.doi.org/10.1016/j.respol.2003.04.001.

Gavião, L. O., Ferraz, F. T., Lima, G. B. A., \& Sant'anna, A. P. (2016). Assessment of the "Disrupt-O-Meter" model by ordinal multicriteria methods. Revista de Administração Inovação, 13(4), 305-314. http://dx.doi.org/10.1016/j.rai.2016.05.002.

Gonçalves, T. J. M., \& Correia, A. R. (2015). Proposta de um modelo para a avaliação da segurança operacional em aeroportos baseado nos métodos De Borda e Promethee 1l. Journal of Transport Literature, 9(1), 50-54. http://dx.doi.org/10.1590/2238-1031.jtl.v9n1a10.

Görög, M. (2016). A broader approach to organisational project management maturity assessment. International Journal of Project Management, 34(8), 1658-1669. http://dx.doi.org/10.1016/j.jproman.2016.08.011.

Hung, S.-Y., Chen, C., \& Wang, K.-H. (2014). Critical success factors for the implementation of integrated healthcare information systems projects: an organizational fit perspective. Communications of the Association for Information Systems, 34(1), 775-796. http://dx.doi.org/10.17705/1CAIS.03439.

lamratanakul, S., F. Badir, Y., Siengthai, S., \& Sukhotu, V. (2014). Indicators of best practices in technology product development projects: prioritizing critical success factors. International Journal of Managing Projects in Business, 7(4), 602-623. http://dx.doi. org/10.1108/1JMPB-06-2012-0036. 
Ihuah, P. W., Kakulu, 1. 1., \& Eaton, D. (2014). A review of Critical Project Management Success Factors (CPMSF) for sustainable social housing in Nigeria. International Journal of Sustainable Built Environment, 3(1), 62-71. http://dx.doi.org/10.1016/j.jisbe.2014.08.001.

Kock, A., Heising, W., \& Gemünden, H. G. (2016). A contingency approach on the impact of front-end success on project portfolio success. Project Management Journal, 47(2), 115-129. http://dx.doi.org/10.1002/pmj.21575.

Kuo, T. H., \& Kuo, Y. L. (2010). The effect of corporate culture and total quality management on construction project performance in Taiwan. Total Quality Management \& Business Excellence, 21(6), 617-632. http://dx.doi.org/10.1080/14783363.2010.483074.

Langston, C., \& Ghanbaripour, A. N. (2016). A Management Maturity Model (MMM) for project-based organisational performance assessment. Construction Economics and Building, 16(4), 68-85. http://dx.doi.org/10.5130/AJCEB.v16i4.5028.

Liang, C., Lu, W., Rowlinson, S., \& Zhang, X. (2016). Development of a multifunctional BIM Maturity model. Journal of Construction Engineering and Management, 142(11), 1-9. http://dx.doi.org/10.1061/(ASCE)C0.1943-7862.0001186.

McLean, 1. (1990). The Borda and Condorcet principles: three medieval applications. Social Choice and Welfare, 7(2), 99-108. http:// dx.doi.org/10.1007/BF01560577.

Meskendahl, S. (2010). The influence of business strategy on project portfolio management and its success: a conceptual framework. International Journal of Project Management, 28(8), 807-817. http://dx.doi.org/10.1016/j.jproman.2010.06.007.

Müller, R. J. R. (2016). The impact of project methodologies on project success in different project environments. International Journal of Managing Projects in Business, 9(2), 1-38. http://dx.doi.org/10.1108/1JMPB-03-2015-0025.

Nguyen, T. H. D., Chileshe, N., Rameezdeen, R., \& Wood, A. (2019). Stakeholder influence strategies in construction projects. International Journal of Managing Projects in Business, 13(1), 47-65. http://dx.doi.org/10.1108/1JMPB-05-2018-0093.

Nilashi, M., Zakaria, R., lbrahim, O., Majid, M. Z. A., Zin, R. M., \& Farahmand, M. (2015). MCPCM: a DEMATEL-ANP-Based multicriteria decision-making approach to evaluate the critical success factors in construction projects. Arabian Journal for Science and Engineering, 4O(2), 343-361. http://dx.doi.org/10.1007/s13369-014-1529-1.

Pan, J.-N., \& Nguyen, H. T. N. (2015). Achieving customer satisfaction through product-service systems. European Journal of Operational Research, 2471), 179-190. http://dx.doi.org/10.1016/j.ejor.2015.05.018.

Papadonikolaki, E., Verbraeck, A., \& Wamelink, H. (2017). Formal and informal relations within BIM-enabled supply chain partnerships. Construction Management and Economics, 35(8-9), 531-552. http://dx.doi.org/10.1080/01446193.2017.1311020.

Patanakul, P., \& Milosevic, D. (2009). The effectiveness in managing a group of multiple projects: factors of influence and measurement criteria. International Journal of Project Management, 27(3), 216-233. http://dx.doi.org/10.1016/j.ijproman.2008.03.001.

Patanakul, P. (2015). Key attributes of effectiveness in managing project portfolio. International Journal of Project Management, 33(5), 1084-1097. http://dx.doi.org/10.1016/j.jproman.2015.01.004.

Qi, S., Chen, W., Zhang, Y. B., Wu, J. J., \& Cai, J. Z. (2014). ldentification of influence factors and establishment of evaluation index system for OPM3 in mega construction engineering enterprise. Applied Mechanics and Materials, 584-586, 2233-2238. http://dx.doi. org/10.4028/www.scientific.net/AMM.584-586.2233.

Rocha, P. M., Barros, A. P., Silva, G. B., \& Costa, H. G. (2016). Analysis of the operational performance of brazilian airport terminals: a multicriteria approach with De Borda-AHP integration. Journal of Air Transport Management, 51, 19-26. http://dx.doi.org/10.1016/j. jairtraman.2015.11.003.

Silva, E. J. C. (2015). Aplicação do Método de Borda para avaliar as decisões coletivas: um estudo sobre a avaliação de processos críticos afetados pela estratégia de uma empresa do setor elétrico. In Anais do XXXV Encontro Nacional de Engenharia de Produção. Rio de Janeiro: ABEPRO.

Voss, M. (2012). Impact of customer integration on project portfolio management and its success: developing a conceptual framework. Special Issue on Project Portfolio Management, 30(5), 567-581. http://dx.doi.org/10.1016/j.jproman.2012.01.017.

Xiao, J.-H., Xie, K., \& Wan, X.-W. (2010). Key factors influencing enterprise to improve IT application level: Stage difference research: an empirical research on 165 enterprises through field study. In Proceedings of the International Conference on Management Science and Engineering. New York: IEEE. http://dx.doi.org/10.1109/1CMSE.2010.5719779.

Young, R., \& Poon, S. (2013). Top management support-almost always necessary and sometimes sufficient for success: findings from a fuzzy set analysis. International Journal of Project Management, 31(7), 943-957. http://dx.doi.org/10.1016/j.jproman.2012.11.013. 